\title{
Review in Industrial Automation
}

\author{
Udit Mamodiya , Priyanka Sharma \\ Research Scholar, Poornima University Ramchandrapura, Vidhani, Sitapura, Jaipur, India
}

\begin{abstract}
Automation or automatic control is the use of various control systems for operating equipment such as machinery, processes in factories, boilers, heat treating ovens, switching in telephone networks, steering and stabilization of ships, aircraft and other applications with minimal or reduced human intervention. The biggest benefit of automation is that it saves labour, save energy, materials and to improve quality, accuracy and precision. The wireless communication technologies are widely applied in the fields like Industrial Automation. Injection molding machines can fasten the molds in either a horizontal or vertical position. Wireless communication and smart sensors and actuators pose means to sustainably improve automation technology. To learn about Industrial Automation, a review process involving 2 stage approaches has been undertaken for 15 research papers which were published in the period of year 2000 to year 2013. After an exhaustive review process, four key issues were found "Controlling method of injection molding machine for new technologies, new trends in industrial Automation, Energy Storage in co-generation power plant \& Wireless Data Transmission" which is mostly need to enhance of Industrial Automation aspects to get better solution approach. The outcome of the review was in the form of various findings, found under various key issues. The findings included algorithms and methodologies used to solve particular research problem, along with their strengths and weaknesses and the scope for the future work in the area.
\end{abstract}

Key words: Co-generation power plant, Data Transmission, VDF

\section{Introduction}

The plastic injection molding machine control system is composed of driving system and electronic controller. There are three forms of electronic controller which include traditional relay controller, PLC controller and microcomputer controller. A traditional relay controller has less been applied at present, because this have complexity hardware, low precision and difficult for adjusting and maintaining. The PLC controller have many benefits, such as features high reliability, easy programming, strong anti-interference ability and easy maintenance and so on, but the cost is much high. ZigBee is the only standards-based wireless technology designed to address the unique needs of low-cost, low-power wireless sensor. IEEE standard 1588 is a faster approach for control mechanism and the best part of IEEE 1588 that it removes delay of the process. Energy storage of the power plant becomes easier by using modern approach of energy storage system. Capacitor bank can be extended easily whenever their required value needed to improve.

\section{Review Process Adopted}

A literature review is necessary to know about the research area and what problem in that area has been solved and need to be solved in future. This review process approach was divided into five stages in order to make the process simple and adaptable. The stages were:-

Stage 0: Get a "feel"

This stage provides the details to be checked while starting literature survey with a broader domain and classifying them according to requirements.

\section{Stage 1: Get the "big picture"}

The groups of research papers are prepared according to common issues \& application sub areas. It is necessary to find out the answers to certain questions by reading the Title, Abstract, introduction, conclusion and section and sub section headings.

\section{Stage 2: Get the "details"}

Stage 2 deals with going in depth of each research paper and understand the details of methodology used to justify the problem, justification to significance \& novelty of the solution approach, precise question addressed, major contribution, scope \& limitations of the work presented. 


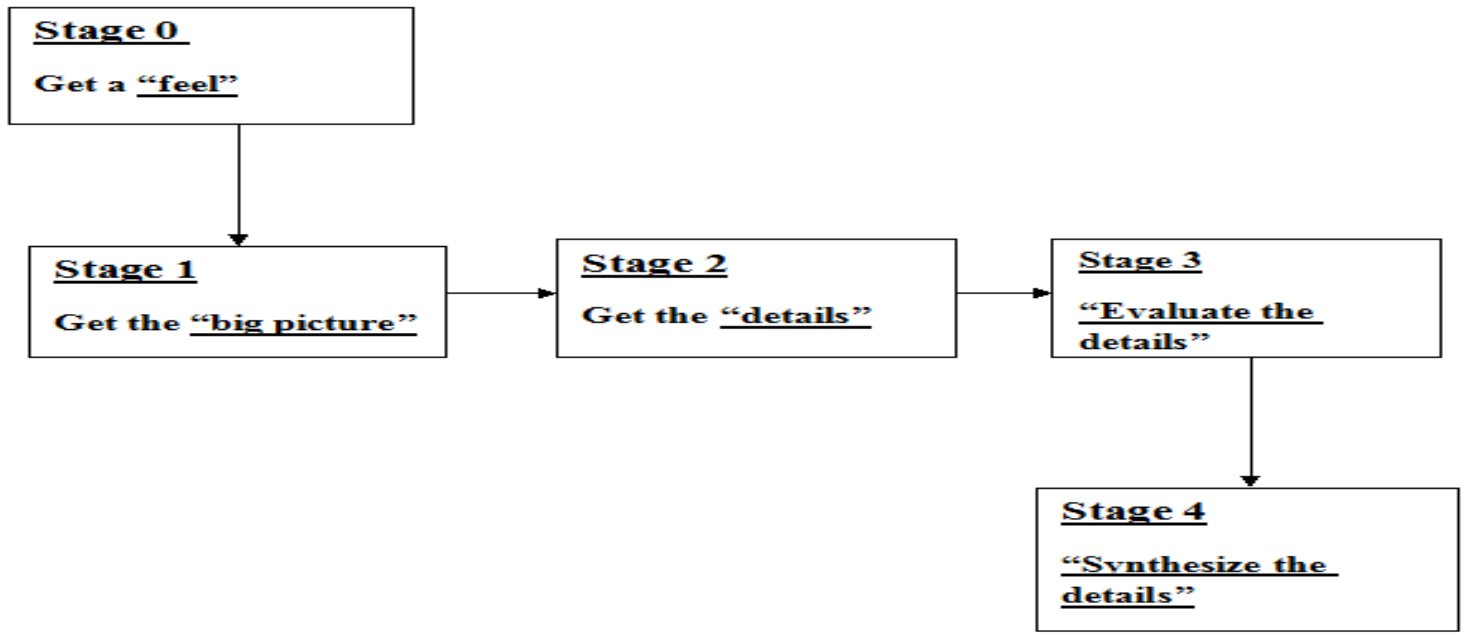

Fig: 2.1 Review Process Adopted

\section{Stage 3: "Evaluate the details"}

This stage evaluates the details in relation to significance of the problem, Novelty of the problem, significance of the solution, novelty in approach, validity of claims etc.

\section{Stage 3+: "Synthesize the detail"}

Stage $3+$ deals with evaluation of the details presented and generalization to some extent. This stage deals with synthesis of the data, concept $\&$ the results presented by the authors.

\section{Various Issues In The Area}

After reviewing 15 research papers on Controlling Parameters of Injection Molding Machine we have found following issues, which has to be addressed, while the designing and implementation of the Injection Molding Machine these issues are:

1) Controlling method of injection molding machine for new technologies

2) New trends in industrial Automation

3) Energy Storage in co-generation power plant

4) Wireless Data Transmission

\section{Issue Wise Discussion}

\section{Issue 1:- Controlling method of injection molding machine for new technologies}

Controlling method of injection molding machine for new technologies is one of the issue, some approaches were used for this issue which is injection molding machine controlling process very hard with relay logic, so embedded system controlling process (logic) used for injection molding machine, this process is better than the relay logic \& it provides an effective \& easy way to control the hydraulic system. The increasing complexity of automation applications needs new framework architecture to development automation control system. By using automation components like that component oriented design, reusability \& picture structure is better way for reduces increasing complexity of automation. This approach reduces valuable development time because the component can be tested with their internal test functionality. By using hardware structure, system software architecture \& experimental plate form give a better approach to development of a distributed control system for PLC based applications. PLC based applications \& technology is very effective and useful technique to improve product quantity \& quality.

\section{Issue 2:- New trends in industrial Automation}

New trends in industrial Automation is second issue, some approaches were used for this issue which is simulation approach for speed control of Induction motor using Lab view software. Lab view software is one of the most significant software \& with the help of LABVIEW, today's industries control applications are done by remote processes only, user normally sits somewhere safe place away from the working environment from there he/she has to control the plant and also make sure that the system parameters should be optimized so here simulation Software plays a vital role in Industrial Monitoring and Control system. Actually the main issue in the designing field is that most of the problems occur while using large no. of control circuits, since increase in 
no. of control circuits lead to superfluous no. of wires. To reduce the no of hardwire circuits and to see things moving or happening graphically can be easily seen so we can implement these circuits on simulation level using Simulation software. Even it is not possible to design control of distant systems as this would involve large no hard wire circuits, Simulation programs have made engineering design easy and with lesser amount of material requirement. It claims that choosing Lab View as the human machine interface for the implementation is a proper decision as it has various types of application $\mathrm{s}$ and functions that are easy to understand and use, secondly this approach is more economical as the objectives and system defects can be identified without the implementation of the circuit. To be precise, this paper falls under the area of controlling an induction motor and its variable like speed and direction with the help of LAB VIEW, but there is again a problem occurs with this simulation software as this is not sufficient because it couldn't fetch the desired result and even in controlling the speed there are only3 multilevel references in the VDF, so we need to improve this for the better controlling and simulation.

\section{Issue 3:- Energy Storage in co-generation power plant}

Energy Storage in co-generation power plant is third issue, some approaches were used for this issue which is comparison of two methods of electrical power storage.One of them is conventional method on other side another is modern system. In conventional power storage method has taken the battery storage method and in modern method has taken capacitor bank method for electrical storage. It's not sufficient because new installation of capacitor bank storage contain many difficulties and connection complex-city. By some of the way tried to solve the problem of conventional storage of electricity by giving a better alternative for electrical storage. Limitation of the given alternative is so much similar to the conventional method al-thought this is only suggested method of the electrical power storage. With the less complexity of the circuitry and the less economical investment this will become a better alternative for electrical storage in solar plants.

\section{Issue 4:- Wireless Data Transmission}

Wireless Data Transmission is fourth issue, some approaches were used for this issue which is Engineering Approach for Secure and Safe Wireless Sensor and Actuator Networks for Industrial Automation Systems which includes the security concept in context of industrial automation and It gives an introduction of a holistic networks but still easy to implement approach for automation networks. Justification of problem illustrated through the holistic approaches including security protocols and also works on VEST (Virginia Embedded Systems Toolkit) focuses on the development of effective composition. But a gap is that a security solution must ensure that the cost of an attacker to break the security solution is higher than his/her potential benefit. Solution approach obtained through an engineering methodology to cope with security requirements in context with industrial automation. Data collected and analyzed through the three stages of solution - the development flow, inputs of the selection process, mapping from requirements to practical solutions. The proposed development flow promises a reliable objective engineering of proper system solutions. Key concepts of the flow are a holistic goal description and an iterative composition algorithm that inherently applies and extends existing knowledge. This Holistic approach is reliable, safe and secure. Applications of Short-Range Wireless Technologies to Industrial Automation: A ZigBee Approach. Bluetooth, ultra-wideband (UWB), ZigBee, and Wi-Fi are four popular wireless standards for short-range communications. Specifically, ZigBee network is an emerging technology designed for low cost, low power consumption and low-rate wireless personal area networks with a focus on the device-level communication for enabling the wireless sensor networks. ZIGBEE develops a wireless network which should be low power consumptive with low cost. Hence, it has been becoming widely used in many applications, such as home automation, industrial control, location and position, telecommunication, and wireless sensor networks.

\section{Issue Wise Solution Approaches Used}

The solution approaches under the various issues have been shown in the Table 6.1 to 6.4, which includes additional information like hardware, software, variable/parameters used along with results obtained. The same table also describes the Comparative analysis between various solution approaches. 


\section{Issue Wise Discussion On Results}

Issue 1:- Controlling method of injection molding machine for new technologies

\begin{tabular}{|c|l|l|}
\hline S. No. & \multicolumn{1}{|c|}{ Solution Approach } & \multicolumn{1}{|c|}{ Results } \\
\hline $\mathbf{1}$ & Injection Speed Controlling Algorithm & Product quantity increases \\
\hline $\mathbf{2}$ & Numerical Control of Machine Tools & $\begin{array}{l}\text { Reduce dangerous ,boring \& difficult jobs in } \\
\text { manufacturing plant }\end{array}$ \\
\hline $\mathbf{3}$ & $\begin{array}{l}\text { Class 1 PC programming software, Class 2 PC monitoring } \\
\text { software }\end{array}$ & Flexibility, Scalability increase \\
\hline $\mathbf{4}$ & Direct Teaching Algorithm & Automation operation easy for not trainer worker \\
\hline $\mathbf{5}$ & Use new Automation components i.e Mechatronical components & Reduce valuable development time \\
\hline
\end{tabular}

\section{Table 6.1 Issue wise Solution Approaches \& Result}

Issue 2:- New trends in industrial Automation

\begin{tabular}{|c|l|l|}
\hline S. No. & \multicolumn{1}{|c|}{ Solution Approach } & \multicolumn{1}{|c|}{ Results } \\
\hline 6 & $\begin{array}{l}\text { LAB VIEW is suggested to be good simulation software } \\
\text { with easy understanding and simple functions. }\end{array}$ & $\begin{array}{l}\text { It is easy to integrate with other devices. It } \\
\text { has less no. of Voltage divider frequency. It } \\
\text { is better software in comparison to other. }\end{array}$ \\
\hline 7 & $\begin{array}{l}\text { IEEE } 1588 \text { algorithm which is actually a time based control } \\
\text { algorithm which is more better over traditional control } \\
\text { techniques like scan-based and many other }\end{array}$ & $\begin{array}{l}\text { It is a faster approach. Removes delay of the } \\
\text { process. It is hard to migrate control devices } \\
\text { particularly I/O to the } 1588 \text { standard. }\end{array}$ \\
\hline 8 & $\begin{array}{l}\text { R-Field bus which is a radio based physical layer based on } \\
\text { the existing and available radio technologies in the LAN. }\end{array}$ & $\begin{array}{l}\text { R-Field bus is a radio based physical layer. } \\
\text { This meet the entire user requirement \& } \\
\text { industrial environment hurdles }\end{array}$ \\
\hline 9 & $\begin{array}{l}\text { The proposed solution relies on a series of simple concept of } \\
\text { new architecture with different layers. }\end{array}$ & $\begin{array}{l}\text { Author defends the solution with new } \\
\text { architecture approach. }\end{array}$ \\
\hline 10 & $\begin{array}{l}\text { Simulation software Lab View, Lab view virtual instrument } \\
\text { development platform is a graphical programming language. }\end{array}$ & $\begin{array}{l}\text { This approach reduces the development } \\
\text { time. DP provides the needed flexibility \& } \\
\text { scalability in control plants design. }\end{array}$ \\
\hline
\end{tabular}

Table 6.2 Issue wise Solution Approaches \& Result

Issue 3:- Energy Storage in co-generation power plant

\begin{tabular}{|c|l|l|}
\hline S. No. & \multicolumn{1}{|c|}{ Solution Approach } & \multicolumn{1}{|c|}{ Results } \\
\hline $\mathbf{1 1}$ & Alternative of energy storing system & $\begin{array}{l}\text { Alternatives for energy storage system proves better } \\
\text { storage system compare to conventional one }\end{array}$ \\
\hline $\mathbf{1 2}$ & Cogeneration heating of working fluid in plant & $\begin{array}{l}\text { Fluid heating can be done in much economical way by } \\
\text { using given method in the paper }\end{array}$ \\
\hline $\mathbf{1 3}$ & Two stage thermal energy storage system & $\begin{array}{l}\text { Plant can be operated in two stages it will reduce the } \\
\text { cogeneration problems }\end{array}$ \\
\hline
\end{tabular}

\section{Table 6.3 Issue wise Solution Approaches \& Result}

Issue 4:- Wireless Data Transmission

\begin{tabular}{|c|l|l|}
\hline S. No. & \multicolumn{1}{|c|}{ Solution Approach } & \multicolumn{1}{c|}{ Results } \\
\hline $\mathbf{1 4}$ & ZIGBEE Technology & $\begin{array}{l}\text { Developing a wireless network which should be low } \\
\text { Power consumptive with low cost \& in reduction of } \\
\text { wiring cost, labour cost \& Maintenance cost. }\end{array}$ \\
\hline $\mathbf{1 5}$ & FRS,TRS Technology & Provides multi-platform solutions for testing \\
\hline
\end{tabular}

\section{Table 6.4 Issue wise Solution Approaches \& Result}

\section{Common Findings}

\section{Issue 1:- Controlling method of injection molding machine for new technologies}

* PLC based applications \& technology is very effective and useful technique to improve product quantity \& quality etc.

* Hydraulic circuit \& microcontroller based embedded system provides an effective \& easy way to control the sequence of injection molding machine.

* Controlling process is very hard with relay logic, so embedded system controlling process used for injection molding machine.

Issue 2:- New trends in industrial Automation 
* Choosing Lab View as the human machine interface for the implementation is a proper decision as it has various types of application $s$ and functions that are easy to understand and use, secondly this approach is more economical as the objectives and system defects can be identified without the implementation of the circuit.

* The area of research is a trend in manufacturing towards faster and higher precision part production with the help of an Application of IEEE 1588 that is Time based control system rather than using traditional control techniques.

* R-Field bus is a radio based physical layer based on the existing and available radio technologies in the LAN and WAN world.

\section{Issue 3:- Energy Storage in co-generation power plant}

* Conventional energy storage system is not reliable compare to the modern energy storage system available in present scenario solar energy storage system should be replaced with the new and modern storage system.

* Solar power tower plant discussed and analysis done for verifying various performances of two-stage thermal energy storage system.

\section{Issue 4:- Wireless Data Transmission}

* The ZIGBEE technology is based on multiple Hop topology formation but it is not based on algorithmic study.

* Zigbee can help continuous monitoring of physical parameters and data transmission in mobile network effectively in terms of cost and power consumption.

* Zigbee can help continuous monitoring of physical parameters and data transmission in mobile network effectively in terms of cost and power consumption. The Modulation technique used in Zigbee Network is Direct Sequence Spread Spectrum (DSSS), which effectively avoid electrical interference. Solution approach obtained through ZIGBEE technology using XBEE trans receiver.

\section{Scope For The Work In Area}

* The automation industry is facing new type of challenges like that information security management.

* The major part of the challenge comes from the diffusion of new ICT technology into the field. Solutions in the field show a strong trend of convergence towards common ICT solutions, especially to IP-based communication and de-facto operating systems.

* This Autonomic Network concept can benefit the productivity of smart applications in smart environment. Investigate the new strategies to improve the security management in Automation field.

\section{Conclusion}

The review of 15 research papers has been carried out in the area of Industrial Automation and find out current challenges and scope of work. After the review, we were found many issues like that Controlling method of injection molding machine for new technologies, New trends in industrial Automation, Wireless Data Transmission \& Energy Storage in co-generation power plant which should be given proper concern, when the enhancement of security takes place. These papers are a survey of different security issues \& controlling related work that carried out in the area of integrity. Propose of these models are to reduce the security risks and improve system reliability.

The technology and trends are changing day by day in industrial automation, nowadays simulation software have made their own place. We can see the plant response be far before starting the plants. Time is also important; IEEE standard 1588 is a fast time based control algorithm to improve the system delays.

The exhaustive review could finally lead to extract findings in the area of Industrial Automation, strengths and weaknesses and scope of work during M. Tech 1st semester Research work.

\section{Acknowledgement}

We would like to express our deep gratitude and thanks to Dr. Mahesh Bundele, Coordinator, Research, M.Tech Poornima University, Jaipur for giving us an opportunity to work under his guidance for our review of research papers and his consistent motivation \& direction in this regard. We extend our sincere thanks to Dr. Manoj Gupta, Provost \& Dean (SET \& SBA) for his continuous support and encouragements throughout the course work.Our thanks are due to Mr. Devendra Kumar Somwanshi, Associate Professor, M. Tech., Poornima University.

Last but not least I would like to thank my parents \& family who always inspired me. I would like to thank the all people who were involved directly or indirectly to complete our review paper work. 


\section{References}

[1]. Allen, J.F.: Maintaining about Temporal Intervals. Comm. of the ACM, 1983 Val 26 Nr 11

[2]. Dorn, J.: Wissensbasierte Echtzeitplanung. Vieweg, 1989 Laffey, Th.J. et al: Real-Time Knowledge-Based Systems.

[3]. AI Maaazine, 1988 Spring, pp 27 - 45. Lauber, R.J: Forecasting Real-Time Behaviour During Software Design using a ASE Environ-Int. Conf. on System Science 1989, pp 645-653.

[4]. Lesser, V.R. and Pavlin, J. and Durfee, E.: Approximate Processing in Real-Time Solving. Maaazine, 1988 Spring, pp 49 - 61.

[5]. McDermott, D.V.: A Temporal Logic for Reasoning About Processes and Plans. Coanitive Science

[6]. Perkins, W.A. and Austin, A.: Adding Temporal Reasoning to Expert-System-Building Environment.

[7]. D. Agrawal, A. El Abbadi, F. Emekci and A. Metwally, 2009, Database Management as a Service: Challenges and Opportunities, Proceedings of The 2009 25th International Conference on Data Engineering, IEEE , pp. 1709-1716.

[8]. Blake, I.F., Kolesnikov, 2006, V. Conditional Encrypted Mapping and Comparing Encrypted Numbers. In: Di Crescenzo, G., Rubin, A. (eds.)FC 2006. Springer, Heidelberg, LNCS, vol. 4107, pp. 206-220.

[9]. D. X. Song, D. Wagner, and A. Perrig, "Practical techniques for searcheson encrypted data," in SP '00: Proceedings of the 2000 IEEE Symposiumon Security and Privacy, 2000, pp. 44-55.

[10]. C. Grigg et al., "The IEEE reliability test system-1996. A report prepared by the reliability test system task force of the application of probability methods subcommittee,"," IEEE Trans. Power Syst., vol. 14, no.3, pp. 1010-1020, Aug. 1999

[11]. R. Bhana, "A production simulation tool for systems with integrated photovoltaic energy resources," M.S. thesis, Dept. Elect. \& Comp. Eng., Univ. of Ilinois, Urbana-Champaign, IL, 2011

[12]. R. Xu and D. C. Wunsch, “partitional clustering”, in Clustering, John Wiley \& SonsInc., Hoboken, New Jersey, pp. 67-72, 2009.

[13]. R. Dominguez, et al., "Optimal offering strategy for a concentrating solar power plant," Applied Energy, vol. 98, pp.316-325, 2012

[14]. G. Gross, "Electricity Resource Planning", class notes for ECE 588, Dept. Elect. \& Comp. Eng., Univ. Ilinois, Urbana-Champaign, Fall 2012.

[15]. NOAA, "Climate Data for Stations," National Oceanic and Atmospheric Admistration, Silver Spring, MD. [Online]. Available: http://www7.ncdc.noaa.gov/CDO/dataproduct

[16]. M. Wagner, "Simulation and Predictive Performance Modeling of Utility-Scale Central Receiver System Power Plants," Dept. Mech. Eng., Univ. Wisconsin, Madison, 2006

[17]. NREL, "Solar Advisor Model," 2012, National Renewable Energy Laboratory, Golden, CO. [Online]. Available: https://sam.nrel.gov/

[18]. A. M. Patnode, "Simulation and Performance Evaluation of Parabolic Trough Solar Power Plants." Dept. Mech. Eng., Univ. Wisconsin, Madison, 2006

[19]. J. L. Sawin et al., "renewable energy 2012 global status report," 2013, REN21, Paris, France. [Online]. Available: http://www.map.ren21.net/GSR/ GSR2012.pdf.

[20]. U. Wang, "the rise of concentrating solar thermal power," 2011, Renewable Energy World.[Online].Available:http://www.renewableenergyworld.com/rea/news/article/2011/06/the-rise-of-concentrating-solar-thermalpower 